\title{
Relationship between sport and physical activity and alcohol consumption among adolescent students in Murcia (Spain)
}

\author{
Francisco J. López Villalba, M.D. ${ }^{a}$, Pedro L. Rodríguez García, M.D. ${ }^{a}$, \\ Eliseo García Cantó, M.D. ${ }^{a}$, and Juan J. Pérez Soto, M.D. ${ }^{a}$
}

\begin{abstract}
Introduction. Sports and physical activity are major components of a healthy lifestyle. The objective of this study was to analyze the relationship between sport and physical activity and alcohol consumption among adolescent students based on gender.

Population and methods. Descriptive, crosssectional, comparative study conducted in adolescent students (aged between 14 and 17 years old) from the Region of Murcia in 2014. Sport and physical activity was assessed using a validated, adapted survey that included both the International Physical Activity Questionnaire and the Monitoring the Future survey. Eleven school facilities from different districts of the Region of Murcia (Spain) participated.

Results. Five hundred and sixty-four adolescent students were included. Among boys, $51.8 \%$ reported to be regularly active, versus $21.8 \%$ of girls. Significant differences were observed in terms of alcohol consumption by gender $(31.1 \%$ for boys versus $48.2 \%$ for girls, $p=0.000$ ). A significant, reverse relationship between sport and physical activity and alcohol consumption was observed among both boys and girls.

Conclusions. The level of sport and physical activity is higher among adolescent boys than girls. Sport and physical activity shows a positive association with a lower level of alcohol consumption among both genders.
\end{abstract}

Key words: alcohol consumption, physical exercise, adolescents, health.

http:/ /dx.doi.org/10.5546/aap.2016.eng.101 and Artistic

Expression,

Universidad de

Murcia, Espinardo

Campus, Murcia,

Spain.

E-mail address:

Francisco J. López

Villalba, M.D.:

paco.lopez@um.es

Funding: This study was internally funded by the School of

Education.

Conflict of interest: None.

Received: 07-09-2015 Accepted: 10-28-2015
Western Pacific and the Americas and the second in Europe. Several investigations on social behaviors related to consumption have confirmed the establishment and development of this legal drug, which has progressively become consolidated as a harmful life habit among adolescents. ${ }^{5,6}$ In addition, alcohol consumption at an early age may have an impact and predict health problems related to alcohol abuse during adulthood. ${ }^{7}$

Sport and physical activity is considered one of the most representative habits of a healthy lifestyle thanks to its positive effects for the prevention of most medical conditions related to a sedentary lifestyle. ${ }^{8}$ Several studies have established the beneficial effects of an adequately planned and systematized sport and physical activity. ${ }^{9,10}$

Different studies have evidenced the protective effect of sport and physical activity against harmful habits among adolescents. Adopting an active lifestyle with regular sport and physical activity is associated with a reduced consumption of toxic substances, including alcohol. ${ }^{11-13}$ Such reverse relationship between regular sport and physical activity and alcohol consumption has not been corroborated by all studies.

Some authors have described a similar or significantly higher level of alcohol consumption among physically active adolescents compared to their sedentary peers. ${ }^{14-16}$

However, all national and international entities consider that participating in sport and physical activity programs may encourage adolescents to spend their leisure 
time doing physical activity instead of doing things related to alcohol consumption. ${ }^{6}$

For all these reasons, the objective of this study was to analyze the relationship between sport and physical activity and alcohol consumption among adolescent students based on gender.

\section{MATERIAL AND METHODS Population}

Descriptive, cross-sectional, comparative study conducted between September and December 2014. Out of a population of 40000 adolescent students aged between 14 and 17 years old, a random sample was selected among 11 school facilities from different districts in the Region of Murcia (Spain). Based on a 95.5\% confidence level and $\mathrm{a} \pm 4.2 \%$ error in calculations, the minimum sample size was estimated to be 538 subjects. The sample was selected out of all students enrolled at $3^{\text {rd }}$ and $4^{\text {th }}$ grades of Obligatory Secondary Education (OSE) and at $1^{\text {st }}$ grade of high school. Selection was based on a random, stratified and multiple stage process with different sampling units (regions, municipalities, school facilities).

The following inclusion criteria were considered: all adolescents who met the selected population requirements, who were present in the classroom on the study day and who had submitted the study informed consent were considered. Adolescents who referred that they did not understand Spanish were considered for exclusion criteria. Finally, having submitted an incomplete questionnaire was considered an elimination criterion.

\section{Procedure}

The study was approved by the Ethics Committee of Universidad de Murcia. Before collecting data, permission was obtained from education authorities and the deans of school facilities. In addition, the study was introduced and described to parents and students, and their informed consent was obtained.

All subjects participated in the study voluntarily. The final questionnaire was designed for self-administration. An investigator who had received training on how to solve students' questions supervised the questionnaire administration process.

For sample analysis, three types of outcome measures were used: sociodemographic (gender, age and grade), sport and physical activity, and alcohol consumption. A 25-item questionnaire was prepared (4 items in relation to physical exercise, 11 items regarding alcohol consumption and 10 items associated with general matters). The questionnaire was first cognitively pretested with a pilot sample of 92 adolescents (41 girls and 51 boys) to determine the level of comprehension of the different items, the time required to administer it and any complications related to its implementation. As a result, certain items were removed and others, modified. Once corrections were made, the definite version of the questionnaire was developed (Annex).

The International Physical Activity Questionnaire (IPAQ) - short form was used to assess sport and physical activity done regularly out of school. ${ }^{17}$ This questionnaire asked about the type of sport activity done out of school, time spent doing it and the day of the week on which it was done. Based on collected data, adolescents were classified into one of the following three categories: inactive (no sport and physical activity at all), irregularly active (some sort of sport and physical activity one to three times a week), and regularly active (sport and physical activity more than three times a week).

The adaptation process was done following the International Test Commission (ITC) recommendations for design and test adaptation. ${ }^{18,19}$

The Monitoring the Future (MTF) survey ${ }^{20}$ was adapted to the context of Spanish adolescents and used to determine alcohol consumption. MTF items related to alcohol consumption were used. Subjects were classified into one of two categories: 1. Regular drinker: subjects who had consumed alcohol at least five times in the past two weeks.

2. Non-alcohol user: subjects who had not consumed alcohol at all or who had consumed less than five alcoholic beverages in the past two weeks.

\section{Data analysis}

For results, descriptive statistics were collected using numeric and percentage count based on gender for categorical outcome measures. For continuous outcome measures, mean and standard deviation values were expressed.

The relationship among categorical outcome measures was established using contingency tables with Pearson's $\chi^{2}$ test with residual analysis (a value of $p<0.05$ was considered significant). Residues account for the differences between observed and expected frequency for each questionnaire box. If $\chi^{2}$ contrast was significant, residues indicate 
what boxes make the greater contribution to the statistical value. A higher residue value describes a higher probability of a certain outcome measure combination, i.e., a box, being significant. Cramer's $\mathrm{V}$ test, odds ratios (ORs) and a 95\% confidence interval $(\mathrm{CI})$ were applied to establish the association among outcome measures.

In addition, to establish the degree of differential influence of independent outcome measures included in this study, a binary logistic regression model was developed and central cutoff points determined by percentile values were established as reference centers for "dummy" scores in overall regular sport and physical activity levels and the different sub-scales. Data were processed and subjected to statistical analysis using the SPSS statistical package, version 15.0.

\section{RESULTS}

The definite sample was made up of 564 subjects (Table 1). All students present in the classroom on the day of the survey completed the questionnaire. Questionnaires completed by 10 adolescents $(2 \%)$ were removed because they were not adequately filled in.

TABLE 1. Characteristics of the population (n: 564)

\begin{tabular}{lccccc}
\hline & Total & \multicolumn{5}{c}{ Age } \\
\cline { 3 - 6 } & $\mathbf{N}(\%)$ & $\mathbf{1 4}$ & $\mathbf{1 5}$ & $\mathbf{1 6}$ & $\mathbf{1 7}$ \\
& & $\mathbf{N}(\%)$ & $\mathbf{N ~ ( \% )}$ & $\mathbf{N}(\%)$ & $\mathbf{N}(\%)$ \\
\hline Boys & $564(100)$ & $112(19.9)$ & $136(24.1)$ & $161(28.5)$ & $155(27.5)$ \\
Girls & $257(45.6)$ & $50(8.9)$ & $62(11)$ & $66(11.7)$ & $79(14)$ \\
\hline
\end{tabular}

TABLE 2. Regular alcohol consumption by gender

\begin{tabular}{lccc}
\hline & Total & \multicolumn{2}{c}{ Regular drinker } \\
\cline { 3 - 4 } & N (\%) & YES & NO \\
& & N (\%) & $336(59.6)$ \\
\hline Total & $564(100)$ & $228(40.4)$ & $117(68.9)$ \\
Boys & $257(45.6)$ & $80(31.4)$ & 4.1 \\
Residual correction & & -4.1 & $159(51.8)$ \\
Girls & $307(54.4)$ & $148(48.2)$ & -4.1 \\
Residual correction & & 4.1 & \\
\hline
\end{tabular}

$\chi^{2}=16.946 ; p=0.000$.

TABLE 3. Sport and physical activity by gender

\begin{tabular}{|c|c|c|c|}
\hline & $\begin{array}{c}\text { Total } \\
\text { N (\%) }\end{array}$ & $\begin{array}{c}\text { Boys } \\
\text { N (\%) }\end{array}$ & $\begin{array}{c}\text { Girls } \\
\text { N (\%) }\end{array}$ \\
\hline & $564(100)$ & $257(45.6)$ & $195(63.5)$ \\
\hline Inactive & $267(47.3)$ & $72(28)$ & $195(63.5)$ \\
\hline Residual correction & & -8.4 & 8.4 \\
\hline Irregularly active & $97(17.2)$ & $52(20.2)$ & $45(14.7)$ \\
\hline Residual correction & & 1.7 & -1.7 \\
\hline Regularly active & $200(35.5)$ & $133(51.8)$ & $67(35.5)$ \\
\hline Residual correction & & 7.4 & -7.4 \\
\hline
\end{tabular}

$\left.\chi^{2}=75.106 ; p=0.000\right)$. 
In relation to alcohol consumption, $40.4 \%$ of adolescents drank alcohol regularly, and the percentage of girls was higher than that of boys (Table 2). The test of independence showed a significant association in the proportion of girls who stated to be regular alcohol drinkers in relation to boys $\left(\chi^{2}=16.946, p=0.000\right)$. The size of the effect of such relationship was 0.173 $(p=0.000)$.

In relation to sport and physical activity, $35.5 \%$ reported being active on a regular basis and $17.2 \%$ were irregularly active, versus $47.3 \%$ who considered themselves inactive. The levels of physical exercise were higher among boys (Table 3), as evidenced by Pearson's $\chi^{2}$ test of independence with residual analysis; a greater positive association with sport activity was observed among boys when compared to girls $\left(\chi^{2}=75.106, p=0.000\right)$. The size of the effect of such relationship was $0.365(p=0.000)$.

Contingency tables and the $\chi^{2}$ test with residual analysis for establishing a relationship between sport and physical activity and alcohol consumption (Table 4) found a positive and significant relationship between boys who reported to be regularly active and a lower probability of alcohol consumption $\left(\chi^{2}=55.05\right.$, $p=0.000)$. The size of the effect of such relationship was $0.463(p=0.000)$. The OR for the association between the regularly active category and no alcohol consumption was 8.67 (95\% CI: 4.69-16.0). The same relationship between both outcome measures was observed among girls $\left(\chi^{2}=65.05, p=0.000\right)$. The size of the effect of such relationship as expressed by Cramer's V test was $0.460(p=0.000)$, with an OR of 8.79
(95\% CI: 4.99-15.49). Alcohol consumption was associated with the inactive category among both boys and girls.

Such distinct exploratory trend in the relationship among outcome measures was confirmed by means of binary logistic regression tests, where b (0.794) and Expb (2.212) values with a -0.790 correlation matrix evidenced that boys who tended to a regular sport and physical activity had a lower probability of alcohol consumption $(p=0.000)$. Such relationship was also significant among girls, with $\mathrm{b}$ and Expb values of 0.072 and 1.074, respectively, and a correlation matrix of -0.521 , so this relationship turned out positive $(p=0.000)$.

\section{DISCUSSION}

As evidenced by other national and international studies, ${ }^{6,12,13,21,22}$ this investigation demonstrated that regular sport and physical activity is positively related to a lower frequency of alcohol consumption among surveyed adolescents. Likewise, most studies have pointed out significant differences in the frequency and percentage of sport and physical activity between boys and girls, indicating that boys did more sport activity than girls;, ${ }^{8,23-25}$ such differences may have an effect on alcohol consumption habits.

The analysis of alcohol consumption data showed that $40.4 \%$ of adolescents stated that they consumed alcohol regularly (31.1\% of boys versus $48.2 \%$ of girls). Similar percentages were referred by Martinsen et al. ${ }^{26}$ for Norwegian adolescents, who evidenced a regular consumption of $46 \%$ among girls and of $31 \%$ among boys. On the contrary, other studies have evidenced higher

TABLE 4. Association tests (Pearson's ${ }^{2}$ test with residual analysis) that establish a relationship between regular sport and physical activity and a habit of alcohol consumption

\begin{tabular}{|c|c|c|c|c|c|c|c|c|c|c|}
\hline \multirow[t]{2}{*}{$\begin{array}{l}\text { Related } \\
\text { outcome }\end{array}$} & \multicolumn{6}{|c|}{$\begin{array}{c}\text { Boy } \\
\text { Regular drinker }\end{array}$} & \multicolumn{4}{|c|}{$\begin{array}{c}\text { Girl } \\
\text { Regular drinker }\end{array}$} \\
\hline & $\begin{array}{c}\text { Yes (n/\%) } \\
\text { ctr }\end{array}$ & $\begin{array}{c}\text { No }(\mathrm{n} / \%) \\
\mathrm{ctr}\end{array}$ & Total & $\chi^{2}$ & $p$-value & $\begin{array}{c}\text { Yes }(n / \%) \\
\text { ctr }\end{array}$ & $\begin{array}{c}\text { No n (\%) } \\
\text { ctr }\end{array}$ & Total & $\chi^{2}$ & $p$-value \\
\hline Inactive & $\begin{array}{c}47(18.3) \\
7.4\end{array}$ & $\begin{array}{c}25(9.7) \\
-7.4\end{array}$ & 72 & & & $\begin{array}{c}128(41.7) \\
8.1\end{array}$ & $\begin{array}{c}67(21.8) \\
-8.1\end{array}$ & 195 & & \\
\hline Irregularly active & $\begin{array}{c}7(2.7) \\
-3.1\end{array}$ & $\begin{array}{c}45(17.5) \\
3.1\end{array}$ & 52 & 55.05 & 0.000 & $\begin{array}{c}8(2.6) \\
-4.4\end{array}$ & $\begin{array}{c}37 \text { (12.1) } \\
4.4\end{array}$ & 45 & 65.5 & 0.000 \\
\hline Regularly active & $\begin{array}{c}26(10.1) \\
-4.2\end{array}$ & $\begin{array}{c}107(41.6) \\
4.2\end{array}$ & 133 & & & $\begin{array}{c}12(3.9) \\
-5.6\end{array}$ & $\begin{array}{c}55(17.9) \\
5.6\end{array}$ & 67 & & \\
\hline Total & 80 & 177 & 257 & & & 148 & 159 & 307 & & \\
\hline
\end{tabular}

$\mathrm{N}=$ subject frequency; $\%$ = percentage.

$\mathrm{ctr}=$ corrected typified residuals.

$\chi^{2}=$ Pearson's ${ }^{2}$ test. 
consumption percentages $(63 \%$ according to the State Survey on the Use of Drugs in Secondary Education [Encuesta Estatal sobre Uso de Drogas en Enseñanzas Secundarias $]^{1}$ and $53.9 \%$ according to the data collected by the Health Board of the Murcia Region). ${ }^{25}$ Other studies indicated a 25$27 \%$ regular alcohol consumption among North American ${ }^{20}$ and Icelandic ${ }^{12}$ adolescents.

Gender acted as an outcome measure that had an impact on alcohol consumption patterns. This study evidenced a higher and statistically significant proportion of girls who drink alcohol (17\% more among girls than boys). A similar relationship was observed in a study conducted by Tur et al., ${ }^{21}$ who demonstrated that $65 \%$ of girls consumed alcohol versus 53\% of boys. Likewise, in the European School Survey Project on Alcohol and Other Drugs (ESPAD) study, conducted in different European countries (Sweden, Iceland, Norway, Finland, Estonia and Lithuania), a higher level of alcohol consumption was observed among women.

A retrospective analysis of the different studies comparing consumption based on gender shows that there has been a sensitive reduction in gender differences, resulting in a trend towards similar consumption rates. Such trend may be the consequence of increased independence of women. ${ }^{28}$ Not with standing this, boys continue to show a higher alcohol consumption rate than girls. ${ }^{29}$ However, the subjective feeling of intoxication is greater among girls with the same level of blood alcohol than boys. ${ }^{30}$

One of the most important aspects in the relationship between sport and physical activity and alcohol consumption is the interaction between these outcome measures. The analysis conducted in this study evidences that regular sport and physical activity is positively related to a lower regular alcohol consumption among adolescents, and that such relationship differs depending on gender. In this regard, Ruiz-Juan et al. ${ }^{6}$ conducted a study in adolescents from different education levels and found a significant relationship during the secondary school stage. Likewise, Tur et al. ${ }^{21}$ studied 445 adolescents aged between 14 and 18 years old and found that those who did more sport and physical activity consumed less alcohol. Similarly, TerryMcElrath et al. ${ }^{13}$ observed a positive relationship between sport activity and alcohol consumption among North American 13-14 year-old students. On the contrary, such relationship was not observed among adolescents who frequently took part in group sports. In addition, Werch et al. ${ }^{22}$ implemented an intervention program that included sport and physical activity in a group of North American adolescents. When results were compared against a control group who had not taken part in the program, Werch et al. found that alcohol consumption had been lower in the intervention group. In this regard, Kristjansson et al. ${ }^{12}$ conducted a study in 3117 Icelandic adolescents aged between 14 and 15 years old who were separated into two groups: an intervention group with adolescents who did sports and received health-related information, and a control group. Following data analysis, the intervention group evidenced a lower alcohol consumption level than the control group.

Based on the analysis of these investigations, it may be suggested that sport and physical activity is associated with a lower prevalence of alcohol consumption in these age groups. Such practice may have a protective and preventive effect against unhealthy habits among adolescents. ${ }^{29}$ In our study, it was observed that adolescents who reported to do sport and physical activity are associated with a negative alcohol use, among both girls and boys. For this reason, we may state that sport and physical activity may be a valid indicator to promote a healthy lifestyle among adolescents, although certain studies have found a reverse association. ${ }^{14,16}$ In this regard, Lisha et al. ${ }^{15}$ reviewed studies on the participation in sport activity and alcohol consumption and found only two out of 29 studies had shown a positive relationship between both outcome measures.

This study poses several limitations that should be taken into consideration. First of all, this is a descriptive study and, therefore, no causative assumptions may be made based on collected data. Secondly, the study's crosssectional nature is a limitation for establishing directionality in observed associations. It is necessary to focus more deeply on other outcome measures that may interact in the relationship between sport and physical activity and alcohol consumption.

Sport and physical activity may have an inhibitory effect against alcohol consumption among adolescents. It may be suggested that regular sport and physical activity out of school is related to a lower prevalence of alcohol consumption; therefore, there is a lower probability of finding adolescents who drink alcohol among those who spend more time doing physical activity during their leisure time. 
It is necessary for public organizations to foster sport and physical activity among adolescents, especially girls, and to create health promotion centers by means of sport and physical activity aimed at improving adolescent well-being so as to increase leisure time spent doing it. ${ }^{3,22}$

To sum up, almost half of adolescents consume alcohol, and consumption rates are higher among girls. On the contrary, girls have evidenced lower levels of sport and physical activity than boys. Sport and physical activity is negatively associated with alcohol consumption among both girls and boys.

\section{Acknowledgments}

To the entire faculty of the Secondary Education facilities where surveys were administered. To the Education, Training and Labor Board for facilitating the authorization to conduct the study at the selected facilities.

\section{REFERENCES}

1. España. Ministerio de Sanidad, Servicios Sociales e Igualdad. Encuesta Estatal sobre Uso de Drogas en Estudiantes deEnseñanzaSecundaria(ESTUDES), 1994-2010. [Accessed on: October 30, 2015]. Available at: http:/ /www.pnsd.msssi.gob.es/profesionales/sistemasInformacion/sistemaInformacion/ pdf/ESTUDES_2010.pdf.

2. Sánchez-Ventura JG, Grupo Prev Infad. Prevención del consumo de alcohol en la adolescencia. Rev Pediatr Aten Primaria 2012;14(56):335-42.

3 Orgaz Gallego MP, Segovia Jiménez M, López de Castro F, Tricio Armero MA. Consumo de alcohol en escolares toledanos: motivos y alternativas. Aten Primaria 2005;36(6):297302.

4. Organización Mundial de la Salud. Alcohol. Nota descriptiva $\mathrm{N}^{\circ}$ 349. Ginebra, 2015. [Accessed on: October 28, 2015]. Available at: http://www.who.int/mediacentre/ factsheets/fs349/es/.

5. Galán I, Rodíguez-Artalejo F, Díez-Gañán L, Tobías A, et al. Clustering of behavioural risk factors and compliance with clinical preventive recommendations in Spain. Prev Med 2006;42(5):343-7.

6. Ruiz-Juan F, De la Cruz-Sánchez E, García-Montes ME. Motivos para la práctica deportiva y su relación con el consumo de alcohol y tabaco en jóvenes españoles. Salud Pública Méx 2009;51(6):496-504.

7. Riala K, Hakko H, Isohanni M, Järvelin MR, et al. Teenage smoking and substance use as predictors of severe alcohol problems in late adolescence and in young adulthood. J Adolesc Health 2004;35(3):245-54.

8. Rodríguez García PL, López Villalba FJ, López Miñarro PA, García Cantó E. Práctica de ejercicio físico y su relación con el consumo de tabaco en adolescentes. Diferencias entre géneros. Adicciones 2013;25(1):29-36.

9. Pate RR, Saunders R, Dishman RK, Addy C, et al. Longterm effects of a physical activity intervention in high school girls. Am J Prev Med 2007;33(4):276-80.

10. Telama R, Yang X, Viikari J, Välimäki I, et al. Physical activity from childhood to adulthood: a 21-year tracking study. Am J Prev Med 2005;28(3):267-73.

11. Pastor Y, Balaguer I, García-Merita M. Relaciones entre el autoconcepto y el estilo de vida saludable en la adolescencia media: un modelo exploratorio. Psicothema 2006;18(1):18-24.

12. Kristjansson AL, James JE, Allegrante JP, Sigfusdottir ID, et al. Adolescent substance use, parental monitoring, and leisure-time activities: 12-year outcomes of primary prevention in Iceland. Prev Med 2010;51(2):168-71.

13. Terry-McElrath YM, O’Malley PM, Johnston LD. Exercise and substance use among American Youth, 1991-2009. Am J Prev Med 2011;40(5):530-40.

14. Dever BV, Schulenberg JE, Dworkin JB, O'Malley PM, et al. Predicting risk-taking with and without substance use: the effects of parental monitoring, school bonding, and sports participation. Prev Sci 2012;13(6):605-15.

15. Lisha NE, Sussman S. Relationship of high school and collage sports participation with alcohol, tobacco, and illicit drug use: a review. Addict Behav 2010;35(5):399-407.

16. Rupps E, Haenle MM, Steinacker J, Mason RA, et al. Physical exercise in southern Germany: a cross-sectional study of an urban population. BMJ Open 2012;2(2):e000713.

17. Craig CL, Marshal AL, Sjöström M, Bauman AE, et al. International physical activity questionnaire: 12 -country reliability and validity. Med Sci Sports Exerc 2003;35(8):1381-95.

18. Comisión Internacional de Tests. Directrices internacionales para el uso de los tests. Madrid: Colegio Oficial de Psicólogos; 2000.

19. Muñiz J, Elosua P, Hamblenton RK. Directrices para la traducción y adaptación de los tests: segunda edición. Psicothema 2013;25(2):151-7.

20. Johnston LD, O'Malley PM, Bachman JG, Schulenberg JE. Monitoring the future. National results on drug use: 2012 overview of key findings on adolescent drug use. Ann Arbor: Institute for Social Research; 2013.

21. Tur JA, Puig MS, Pons A, Benito E. Alcohol consumption among school adolescents in Palma de Mallorca. Alcohol Alcohol 2003;38(3):243-8.

22. Werch Ch, Moore MJ, DiClemente CC, Bledsoe R, et al. A multihealth behavior intervention integrating physical activity and substance use prevention for adolescents. Prev Sci 2005;6(3):213-26.

23. Gómez LF, Duperly J, Lucumi DI, Gámez R, et al. Nivel de actividad física global en la población adulta de Bogotá (Colombia). Prevalencia y factores asociados. Gac Sanit 2005;19(3):206-13.

24. Levin S, Lowry R, Brown DR, Dietz WH. Physical activity and body mass index among US adolescents: youth risk behavior survey, 1999. Arch Pediatr Adolesc Med 2003;157(8):816-20.

25. Consejería de Sanidad y Política Social de la Región de Murcia. Consumo de drogas en estudiantes de la Región de Murcia, 2010. Bol Epidemiol Murcia 2012;32(754):61-6.

26. Martinsen M, Sundgot-Borgen J. Adolescent elite athletes cigarette smoking, use of snus, and alcohol. Scand J Med Sci Sports 2014;24(2):439-46.

27. Hibell B, Guttormsson U, Ahlström S, Balakireva O, et al. The 2011 ESPAD report. Substance use among students in 36 European countries. Stockholm: Swedish Council for Information on Alcohol and other Drug; 2012. [Accessed on: October 28, 2015]. Available at: http://www.espad. org/Uploads/ESPAD_reports/2011/The_2011_ESPAD_ Report_FULL_2012_10_29.pdf.

28. Kerr-Corrêa F, Tucci AM, Hegedus AM, Trinca LA, et al. Drinking patterns between men and women in two distinct Brazilian communities. Rev Bras Psiquiatr 2008;30(3):235-42.

29. Ruiz-Juan F, Ruiz-Risueño J. Variables predictoras de consumo de alcohol entre adolescentes españoles. An Psicol 2011;27(2):350-9.

30. Salamó Avellaneda A, Gras Pérez ME, Font-Mayolas S. Patrones de consumo de alcohol en la adolescencia. Psicothema 2010;22(2):189-95. 


\section{ANNEX}

The following questions are related to alcohol consumption.

We expect you to answer all questions.

1. Have you received sufficient information about the harmful effects of alcohol at your school?
A lot
Pretty much.
Little
Not at all

2. Do you think alcohol is a drug?

Yes

No

3. What persons in your circle drink alcohol regularly? (Indicate as many as you think necessary)

My father

My mother

My siblings

My boyfriend/girlfriend

My friends

Other persons (indicate who)

4. Have you ever drunk alcohol? (Indicate “No" if you have only tasted or taken a sip of alcohol) Yes

No

If you answered "No", skip to question 12.

5. How old were you when you first tried alcohol? (Consider that you have not tried alcohol if you have only tasted or taken a sip of alcohol).

$$
\text { years old }
$$

6. Where did you first try alcohol? (Indicate only one place)

On the street

At home or at a friend's house

In a bar/disco

Other (indicate where)

7. Who offered you alcohol for the first time? (Indicate only one place)

My father

My mother

A friend

A family member (sibling, cousin, aunt/uncle)

Other person (indicate who)

8. Have you drunk at least five alcoholic beverages in the past two weeks? One beverage refers to a glass of alcohol, such as beer, wine, alcohol combinations, cocktail, champagne/cider, a shot, sangria, etc.

Yes

I do not drink

If you answered "Yes", skip to question 9. 
If you answered "I do not drink", skip to question 12.

9. Have you ever got drunk? (to the point that you do not remember what you did the night before) Yes

No $\square===>$ Skip to question 11 .

10. How old were you when you first got drunk? years old

11. Why do you drink alcohol? (Indicate as many as you think necessary)

Because it makes me happier

Because it makes it easier to make friends

Because it helps me act like an adult

Because it helps me have a good time with my friends

Because my friends drink

Because my parents drink

Other (indicate your reasons)

Below you will find a series of issues related to regular physical activity you do in your daily life.

Sport: sport refers to both physical activity (aerobics, footing, muscle-building, etc.) and sports (soccer, basketball, swimming, etc.) done out of school.

Regular sport and physical activity:

12. Do you do any sport or physical activity regularly (at a club, gym, outdoors, etc.) at least once a week?

Yes

No

If you answered "No", skip to question 16.

13. What sport or physical activity is it?

14. How often do you practice it on a weekly basis?

1-2 days

3 days

4 days

5 or more days

15. Approximately how many hours a day do you spend doing it?

30 minutes

30 minutes- 1 hour

1-2 hours

More than 2 hours 
The following questions are related to some basic characteristics about you and your immediate environment. We expect you to answer all questions.

16. What is your gender?

Male

Female

17. How old are you?

years old

18. What grade are you in?

$3^{\text {rd }}$ grade of OSE

$4^{\text {th }}$ grade of OSE

$1^{\text {st }}$ grade of high school

19. How much money do you have available every week?

Less than 10 Euros

10-15 Euros

15-20 Euros

More than 20 Euros

20. At present, are you a member of a sports club?

Yes

No

21. Have you ever repeated a grade?

Yes

No

22. Compared to your classmates, how do you think your health status is?

Better

The same

Worse

23. In general, how old are your friends?

Older than me

The same as me

Younger than me

24. Have you ever failed Physical Education?

Yes

No

THANK YOU FOR YOUR HELP. 